\title{
Study on the Influence and Its Role of Online Music Spread on Musical Culture
}

\author{
Rui Pan ${ }^{1, a}$, Yan Jiang ${ }^{2, b}$ \\ ${ }^{1}$ Jiangxi Teachers College, Yingtan, Jiangxi, 335001 \\ ${ }^{\mathrm{a}}$ email, ${ }^{\mathrm{b}}$ email
}

Keywords: Online Music Spread; Musical Culture; Impact; Effect

\begin{abstract}
Online music spread belongs to a new form of musical communication, it refers to the use of computer network information system, to achieve further spread of music. Online music spread to spread music opened up a new channel to make way for the expansion of music spread so that more people enjoy music is. Based on the analysis of online music propagation characteristics of the further spread of online music influence and role in the musical culture of the analysis, hoping to provide some valuable recommendations for progress and development of music culture.
\end{abstract}

\section{Introduction}

Traditional Music slow in the exchange and use of all there is a big limitation. As for the music transmission network, it belongs to a new form of music transmission, a good solution to slow the spread of traditional music as well as the sharing of the limitations of defects that spread music more convenient and fast. In recent years, many scholars. The study shows that online music spread in the musical culture of the impact and value of the role is significant [1]. In order to promote the progress and development of musical culture, this article on the "online music spread influence and role in the musical culture of" great significance for analysis.

\section{Network Music Communication Characteristics}

Music Communication Network is a new form of musical communication, such forms of communication to improve the speed of propagation of music, while facilitating the exchange of music and cultural information. To sum up, the spread of online music has the following features:

Conventional music spread timeliness is not strong, mainly due to the spread required by many other aspects, on the basis of access, through printing and recording, further steps to achieve delivery at link number of cases, it is difficult to ensure the music spread timeliness [2]. As for the music transmission network, the ability to let the audience enjoy the music timely information needed to avoid the conventional forms of communication multi-link, fully enhance music spread timeliness.

In the case of the spread of the progressive development of the online music initiative very prominent characteristic of the music of the recipient, that can actively select music, then listen, to see whether they like it, if they like it could further download or copy and so on. At the same time, part of the network due to a permissions problem downloading music will be charged a fee, then music recipients also have the right to accept or not to accept the download.

Spread through the network repeated very prominent characteristic of the music, that music appreciation were met in the case of your favorite music can be played repeatedly, appreciation, so that the viewer will be able to meet the music is largely subjective demand, thereby improving the defects of traditional music "disposable" spread [3].

In traditional music propagation, music creators and music listeners are two separate individuals, the lack of communication between the two. As for online music spread, the music creators and music listener can paste it, e-mail and other forms of real-time communication is to achieve, through the exchange of music creators to be able to get some comments or suggestions, so in the future to create more excellent works. As for the music listener, through the exchange platform, but also the opportunity to expand their own to give advice to promote good cultural exchange. 


\section{Influence and Effect Analysis of Network Music in Musical Culture}

In the analysis process, recognizing that many online music propagation characteristics. Combined with the development of online music spread in recent years, we found that the influence and role in the musical culture is very significant, particularly in the following areas:

Online music spread compared with traditional forms of music spread there from time and space significant advantages, the distance and listen to music creators are much closer between, and its influence and role in music education is very obviously. Teachers in the music teaching process, you can use the Internet to transmit platform meets students' actual music information and teaching content, and students can also use the information network platform for music teachers and teaching content of the transmission or reception download, so both teachers and students inter will be to achieve a good teaching "barrier-free" communication [4]. Moreover, this "barrier-free" communication is not subject to time and space constraints, a good closer relationship between teachers and students. On the one hand, to make the work more smoothly carry out teaching, on the other hand so that students learning initiative has been effectively improved. At the same time, the music teaching process, but also can make use of online video, online video teaching realization, this new mode of teaching students receive easily, and communicate through online video, students can express their views, and for learning music problems in the process of asking teachers, teachers will be able to solve problems in time for the students. Furthermore, there are many network music teaching materials, to carry out the actual teaching process, teachers can ask Baidu, Google, HowNet, VIP knowledge platform to collect the required teaching resources, so as to successfully carry out the teaching of music lay a solid basis. All in all, the impact and spread of online music in music education is significant, it is possible to make music education channels are effectively extended; narrow the distance between teachers and students, to further optimize the realization of teaching music to provide adequate and effective protection.

In the musical culture propagation, there is a very common form of that music. Music network communication development process, its impact and the role of music is significant. Before the spread of online music, and since between composers and musical performers due to various factors, such as historical factors, environmental factors and time factors, so that the quality of a good piece of music is difficult to show in front of the viewer . And after the spread of online music appears, it will be able to achieve a good full integration of music and music performances. At the same time, using the Internet as a platform to channel the viewer to watch music also appears more convenient and faster. Mainly because the network has repeated viewing functions performing piece of music, to avoid the spread can only watch live television transmission defects. All in all, the influence of music in online music spread is significant, the value is also very prominent role. Therefore, in order to promote the development of music culture, we need to be fully aware of their role and influence of music performances.

Network music spread prominent feature, because time-sensitive, enabling repeated listening, and information exchange, the network spread to the concept of contemporary music for music lovers also had some impact, and its effect is very significant. On the one hand, the concept of music changed a great extent. For music creators, the music works simply transfer their own music creation to the network platform, such as cool dog, QQ music, music and shrimp 5sing music, online music platform under the approval conditions, we will be able to achieve the spread of music and information exchange [5]. Mentioned above, traditional music propagation, music creators and music listeners are two completely separate entity, but the music spread through the network, will be able to make these two individuals to achieve a good exchange of information, thereby improving the independent individual situation, to enhance the music cultural interaction. At the same time, for music creators, through the network platform, can instantly listen to more music genre, thus breaking the traditional types of music separate situation, when the music creators learn more types of music case, we will be able to liberate their music thinking, music to stimulate creative inspiration lay valid basis. In addition, in the spread of online music environment, people's musical values also occurred a greater degree of change. Involves some music rights require a fee to be able to play, download, and listen in the process does not have the right to choose to listen to, at 
the same time have the right to choose to listen to, in this process, but also to protect the creators of value rights and interests. All in all, in the development of online music spread, people's concept of music has changed, this change can bring some of the challenges and opportunities for the development of musical culture.

\section{Conclusion}

By exploring this article, realize that online music has spread: salient features real-time, proactive, iterative exchanges and so on. At the same time, online music spread influence and role in the musical culture is very significant, use one hand to offer support and teaching resources to support an effective platform for music education; on the other hand can lay the foundation for progress and development of music performances. In addition, it can change the traditional concept of music, to further promote the development of modern music. All in all, the impact of online music spread music culture is significant, it is necessary to improve the online music propagation environment, strengthen the public music education, further lay a solid foundation for the development of our musical culture.

\section{References}

[1] Mao Yu. Under the influence of hairiness Digital Network Media Perspective of music propagation [J]. big stage, 2012,06: 49-50.

[2] Wang Yanmei. effects of music spread on social musical culture [J]. big stage, 2012, 09: 51-52.

[3] Huang Shumin. For Bi affect network music for music creation and dissemination of analysis [J]. Music Space, 2013, 06: 92-93.

[4] Lin Ge. Online music spread influence on young audiences and guidance [J]. Popular Literature, 2013, 21: 193-194.

[5] Jiang Jiang. Affect the spread of online music for music teaching [J]. drama House, 2015,15: 101. 